\title{
Fluorescein angiography during induced ocular hypertension in glaucoma
}

\author{
M. BEST, M. BLUMENTHAL, M. A. GALIN, AND H. TOYOFUKU \\ From the Department of Ophthalmology, New rork Medical College, Center for Chronic Disease, \\ New York
}

Latex and India ink injection studies have shown that elevated intraocular pressure causes a marked decrease in capillary filling in the optic disc and peripapillary area in experimental animals (Hamasaki and Fujino, r967; Ernest and Potts, 1968). These results ${ }_{0}^{\circ}$ have been confirmed by fluorescein angiographic studies in monkeys (Swietliczko and David, I970) and humans (Blumenthal, Gitter, Best, and Galin, I970; Blumenthal, $\dot{\sigma}$

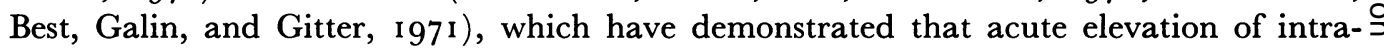
ocular pressure markedly diminishes fluorescence in the disc and peripapillary vasculature. $\vec{c}$

Not infrequently fluorescein angiography in glaucoma patients whose intraocular pressures are within the normal range also reveals a decrease in fluorescence of the optic disc and this has been interpreted as evidence for a decrease in disc vascularity in glaucoma $\frac{\vec{\omega}}{0}$ (Hayreh and Walker, ig67).

If the optic disc vasculature is involved in glaucoma patients, it may be the peripapillary ciliary vasculature that is compromised since these vessels are the major source of blood supply to the optic disc.* The present investigation was undertaken to study the effect of acute elevations of intraocular pressure on the peripapillary choroidal vasculature in patients with glaucomatous cupping of the optic disc.

\section{Materials and methods}

Ten patients with well-controlled open-angle glaucoma were selected for this study. The diagnosis of glaucoma was based on raised intraocular pressure measurements without medication or before surgery, obvious glaucomatous cupping of the disc, and classic visual field defects. Four patients had undergone filtering procedures at least 2 years previously and the remainder were controlled $\frac{5}{3}$ on topical medication.

Four days after discontinuing topical medication one eye in each patient was dilated with I per cent. cyclopentylate and io per cent. phenylephrine. Systolic ophthalmic artery blood pressure was 0 determined by suction ophthalmodynamometry, and intraocular pressure was acutely elevated and maintained above this level using the automated suction ophthalmodynamometer as previously described (Blumenthal and others, 1970). $10 \mathrm{ml} .5$ per cent. fluorescein sodium was then rapidly injected into the antecubital vein and after 10 to 12 seconds the intraocular pressure was slowly decreased by reducing the magnitude of suction. Retinal photographs were recorded at $0 \cdot 5$-sec. O intervals as the amount of suction was progressively decreased. Each photograph was correlated $\mathrm{\omega}$ with intraocular pressure from previously established charts (Galin, Baras, and Cavero, 1969).

Intraocular pressure was measured byapplanation tonometry before dilatation and after fluorescein angiography to be certain that no ocular hypertensive response occurred as a result of the cyclo- $\stackrel{\Phi}{\rightarrow}$ plegic agent (Harris, 1968). The relative intraocular pressure levels at which dye appeared in the retinal and choroidal circulations and the pattern of choroidal filling in the peripapillary area were $\overline{0}$ determined from the photographs. At a subsequent visit fluorescein angiography was repeated in $\overparen{\mathbb{D}}$ the undisturbed eye. 


\section{Results}

At intraocular pressures above the systolic ophthalmic artery blood pressure no dye was seen in the retinal or choroidal vessels. When the intraocular pressure was decreased to levels just below the ophthalmic artery systolic pressure, fluorescein appeared in the central retinal artery and its branches but not in the choroid (Fig. IA). As intraocular pressure was decreased further, dye progressed in the retinal arterioles (Fig. I B). Fluorescein first appeared in the choroidal arteries when intraocular pressure was reduced 7 to I I $\mathrm{mm}$.Hg below that at which dye first became visible in the central retinal artery (Fig. IC). At slightly lower intraocular pressures, isolated patches of dye appeared in the choroid in the posterior pole (Fig. ID).

The peripapillary area was the last part of the choroid to fill with fluorescein as intraocular pressure was lowered. In addition, the filling pattern was irregular. At intra-

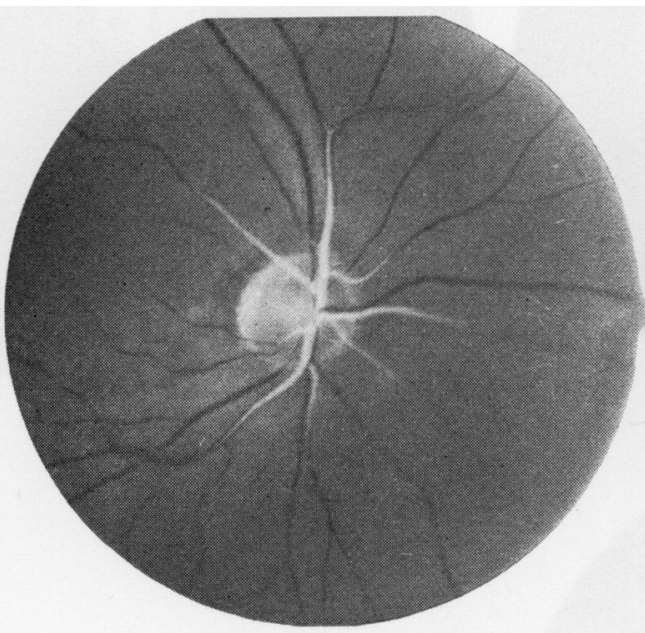

(A) I04 mm.Hg. Dye appears only in branches of central retinal artery

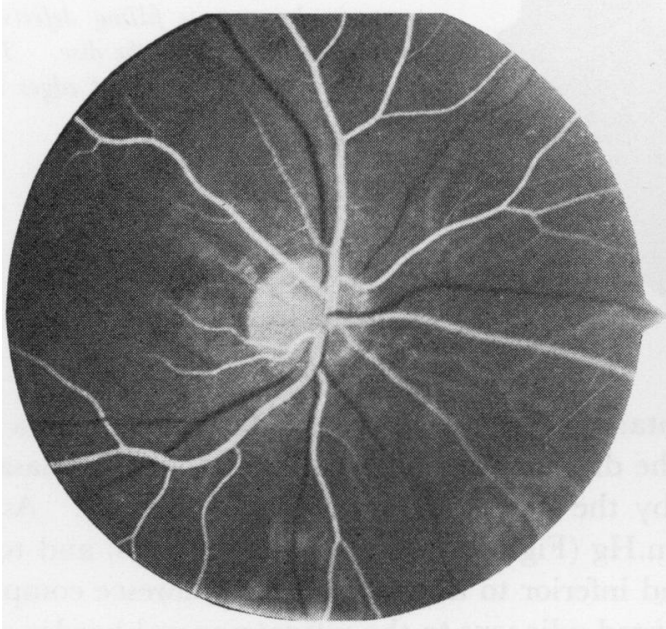

(c) $92 \mathrm{~mm} . \mathrm{Hg}$. Choroidal arteries are visualized

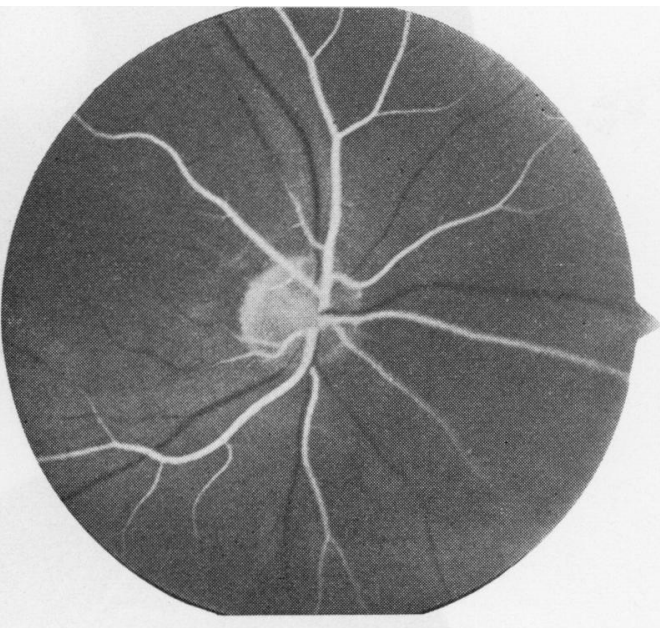

(B) $98 \mathrm{~mm} . \mathrm{Hg}$. Dye progresses in retinal arterioles

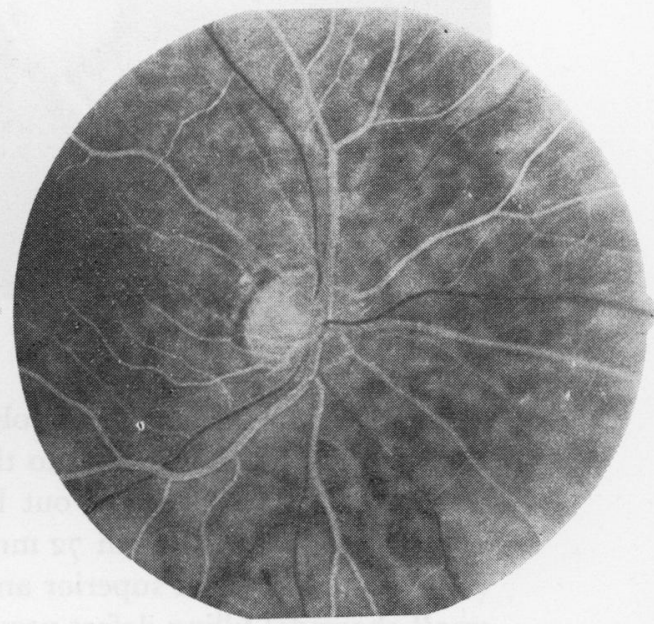

(D) $70 \mathrm{~mm} . \mathrm{Hg}$. Patchy appearance of dye in choriocapillaris

FIG. I Fluorescein angiograms during induced ocular hypertension 
ocular pressures in the vicinity of $60 \mathrm{~mm} . \mathrm{Hg}$, sharply outlined defects in choroidal fluorescence were present on the temporal side of the disc in eight patients. Fig. 2 demonstrates such a defect in juxtapapillary choroidal fluorescence temporal to the disc in a patient with total excavation of the disc and vision reduced to perception of light. As the intraocular pressure was lowered from $80 \mathrm{~mm} . \mathrm{Hg}$ (Fig. 2A) to $68 \mathrm{~mm} . \mathrm{Hg}$ (Fig. 2B), and to $54 \mathrm{~mm} . \mathrm{Hg}$ (Fig. 2C), the defect decreased in size, and it disappeared when intraocular pressure was reduced to $45 \mathrm{~mm} . \mathrm{Hg}$.

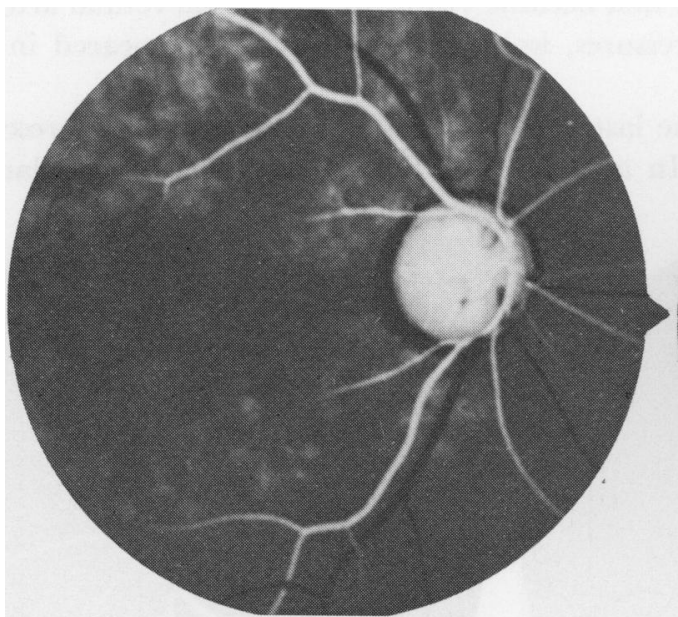

(A) $80 \mathrm{~mm} \cdot \mathrm{Hg}$

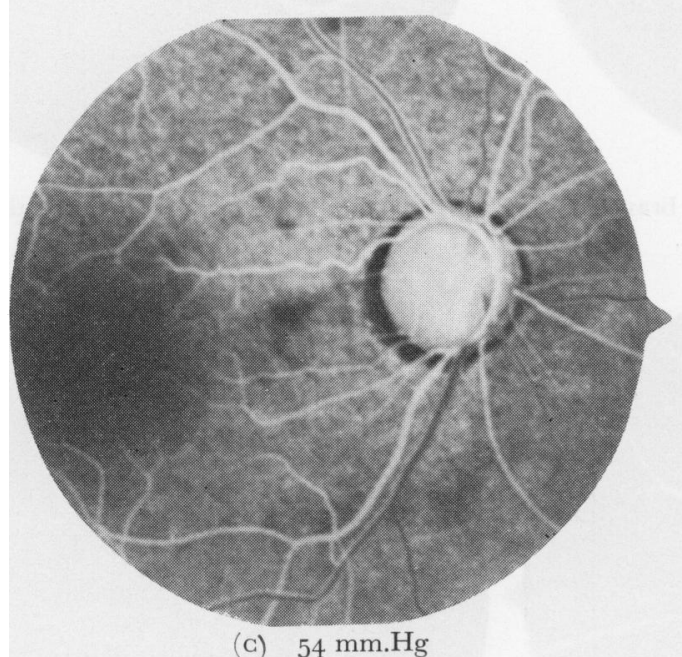

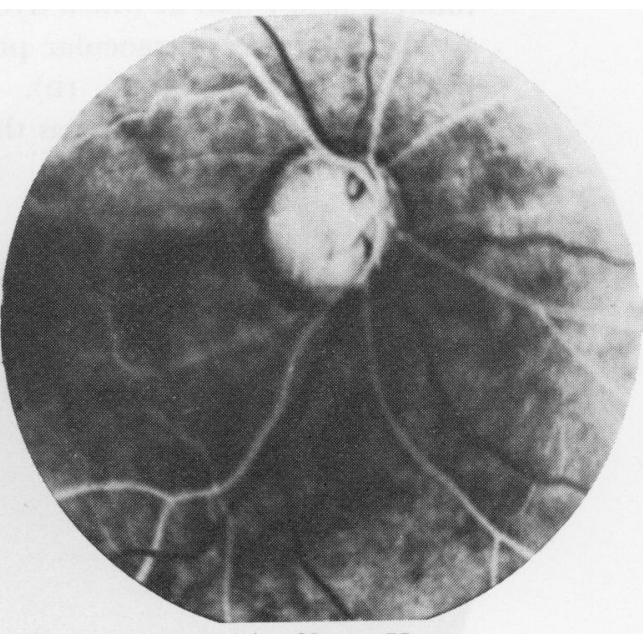

(в) $68 \mathrm{~mm} . \mathrm{Hg}$

FIG. 2 Angiograms at elevated intraocular pressures demonstrate filling defects in choroidal vasculature temporal to the disc. The defect fills with dye from its peripheral edges as intraocular pressure is lowered

Fig. 3 shows the angiograms obtained at elevated intraocular pressures in a patient with cupping that did no' extend to the disc border and who had only superonasal depression of the visual field brought out by the $0.25 \mathrm{~mm}$. test object (Fig. 3D). As intraocular pressure was reduced from $72 \mathrm{~mm} . \mathrm{Hg}$ (Fig. 3A) to $65 \mathrm{~mm} . \mathrm{Hg}$ (Fig. $3^{\mathrm{B}}$ ) and to $55 \mathrm{~mm} . \mathrm{Hg}$ (Fig. 3C), the choroid superior and inferior to the disc did not fluoresce completely, and a small choroidal filling defect persisted adjacent to the inferotemporal border of the disc.

Angiograms of the patient shown in Fig. 4 (overleaf), in whom almost the entire nasal visual field was absent to a $64 \mathrm{~mm}^{2}$ test object (Fig. 4c), revealed a large juxtapapillary 


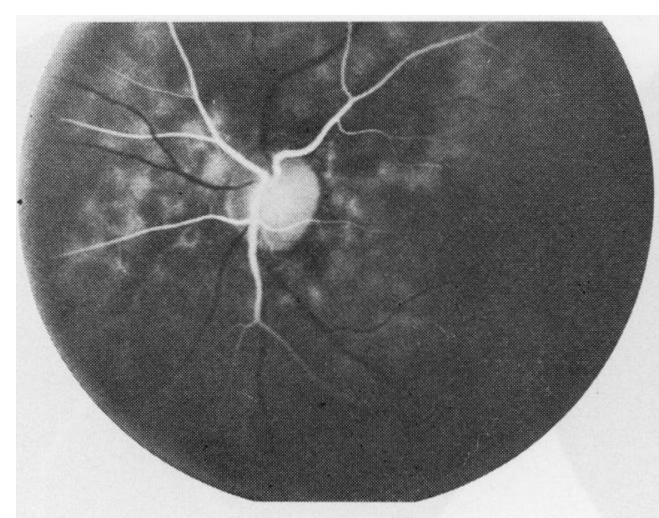

(A) $72 \mathrm{~mm} \cdot \mathrm{Hg}$

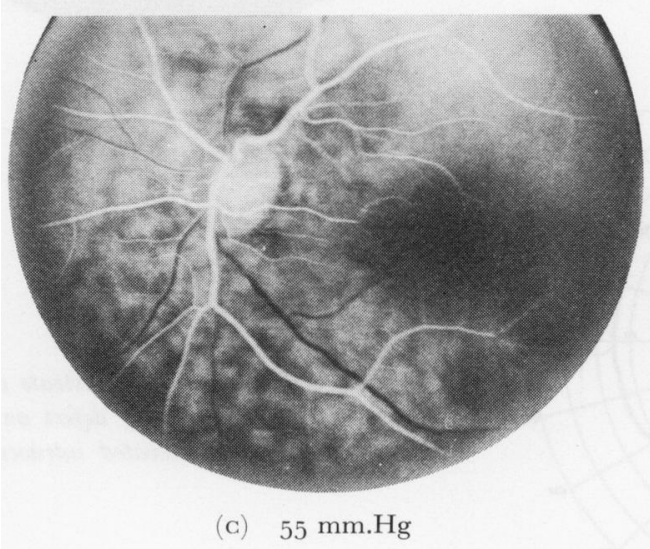

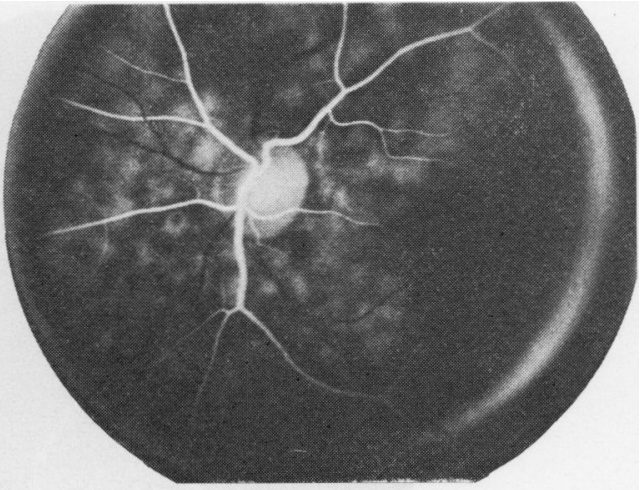

(B) $65 \mathrm{~mm} \cdot \mathrm{Hg}$

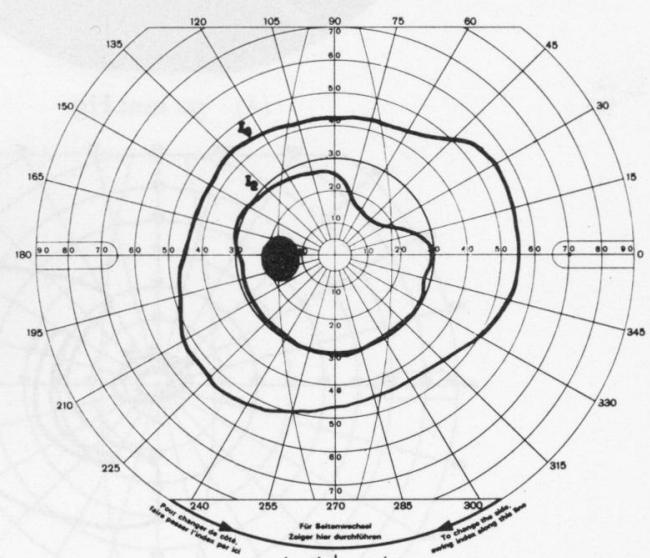

(D) Visual field shows superonasal depression

FIG. 3 Angiograms demonstrate poor filling of choroid above and below the disc and a small choroidal filling defect adjacent to the inferotemporal border of the disc

choroidal filling defect on the temporal side of the disc. The defect had a sharp border and tended to fill with dye from the periphery as intraocular pressure was lowered (Fig. 4A and B).

Fig. 5 (overleaf) shows the fluorescein angiograms obtained in a patient with an inferior arcuate scotoma (Fig. $5^{\mathrm{C}}$ ). At intraocular pressures above $65 \mathrm{~mm} . \mathrm{Hg}$, a large choroidal filling defect was visible adjacent to the temporal border of the disc (Fig. 5A). As the intraocular pressure was lowered, choriocapillaris fluorescence increased in intensity and the choroidal filling defect decreased in size. A sharply outlined defect in choroidal fluorescence adjacent to the superotemporal disc margin persisted, however, at an intraocular pressure as low as $55 \mathrm{~mm} . \mathrm{Hg}$ (Fig. $5^{\mathrm{B}}$ ).

Fig. 6 (overleaf) shows a defect in choroidal fluorescence surrounding the disc at an intraocular pressure of $60 \mathrm{~mm} . \mathrm{Hg}$ (Fig. 6A) in a patient who had severe constriction of the visual field (Fig. 6B). The lack of clarity of the angiogram is due to the presence of a cataract.

Of the eight patients who demonstrated a juxtapapillary choroidal filling defect at elevated levels of intraocular pressure, two had visual acuities of perception of light, one had a superonasal depression of the visual field, two had arcuate scotomata, one had loss of the nasal visual field, and two had severely constricted fields. The size of the choroidal filling defect appeared to bear a direct relationship to the severity of the visual field 


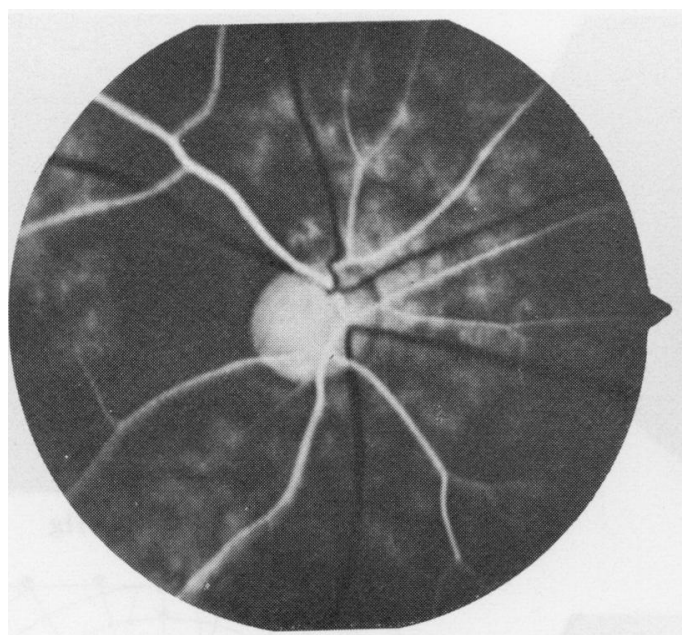

(A) $90 \mathrm{~mm} \cdot \mathrm{Hg}$

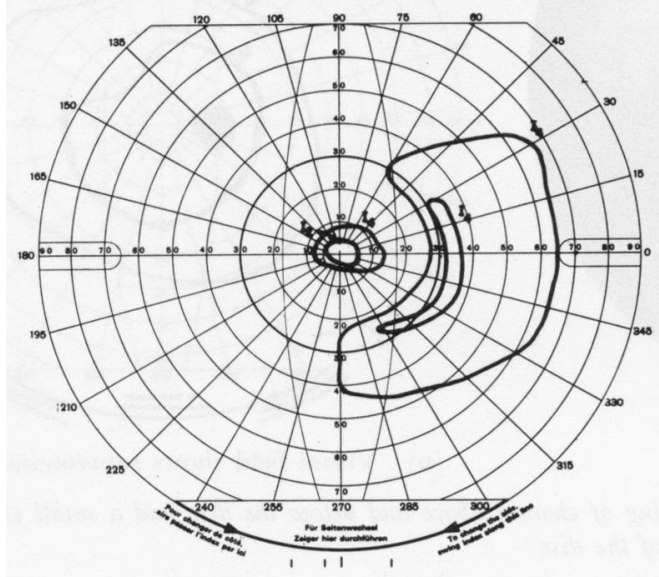

(C) Visual field shows loss of nasal field

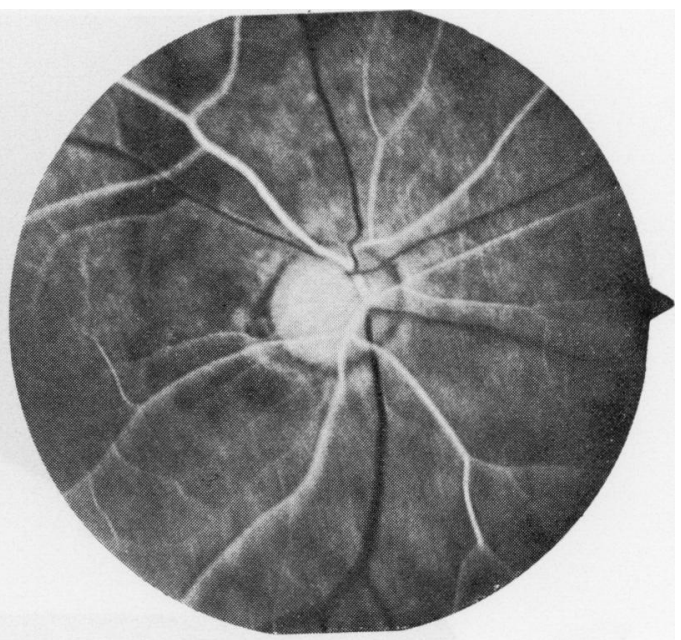

(B) $59 \mathrm{~mm} . \mathrm{Hg}$

FIG. 4 Angiograms demonstrate a large juxtapapillary choroidal filling defect on the temporal side of the disc at elevated intraocular pressures

defect. The two patients who demonstrated no defect in peripapillary choroidal fluorescence had isolated scotomata to the $0.25 \mathrm{~mm}^{2}$ test object in the Bjerrum area in the upper visual field.

\section{Discussion}

The technique employed in this study analyses the pattern and sequence of fluorescence in the retinal and choroidal circulations as intraocular pressure is lowered from levels above the systolic ophthalmic artery blood pressure. Similar studies in patients with normal eyes have shown that at intraocular pressures just below the systolic ophthalmic artery pressure, fluorescein perfuses the retinal arterioles but no dye is visible in choroidal blood vessels (Blumenthal and others, I970, 1971). At lower intraocular pressures, choroidal fluorescence appears at the posterior pole and progresses toward the peripapillary area which becomes uniformly fluorescent at intraocular pressures in the vicinity of $60 \mathrm{~mm} . \mathrm{Hg}$. Simultaneously, small bloodvessels fluoresce within the optic nerve head. The essential feature in the normal patient is that peripapillary choroidal fluorescence occurs in a uniform fashion and no areas appear to be devoid of dye at intraocular pressures of about $60 \mathrm{~mm} . \mathrm{Hg}$. 


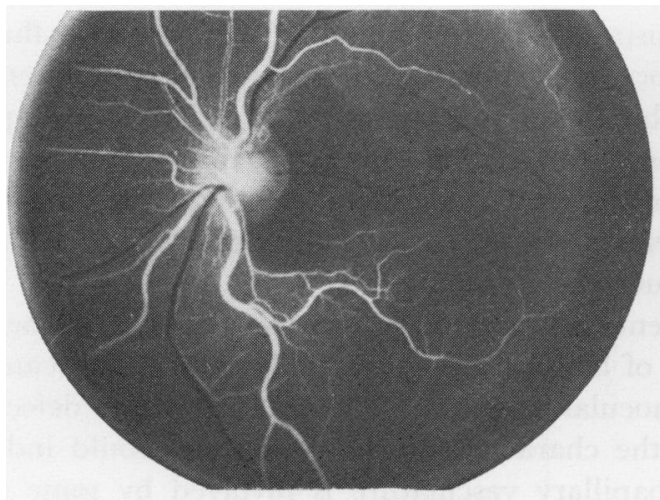

(A) $88 \mathrm{~mm} \cdot \mathrm{Hg}$

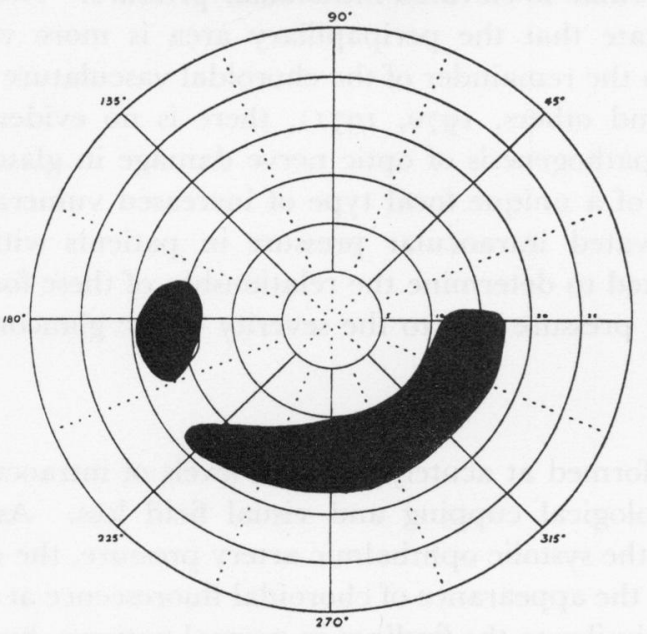

(c) Visual field shows inferior arcuate scotoma

(A)

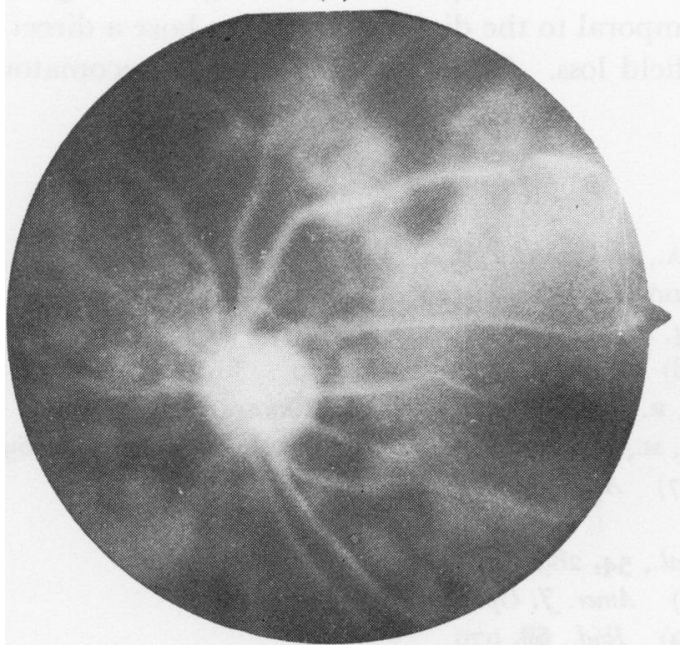

FIG. 6 (A) Angiogram at $60 \mathrm{~mm} . \mathrm{Hg}$ reveals a choroidal filling defect surrounding the disc (B) Visual field is severely constricted

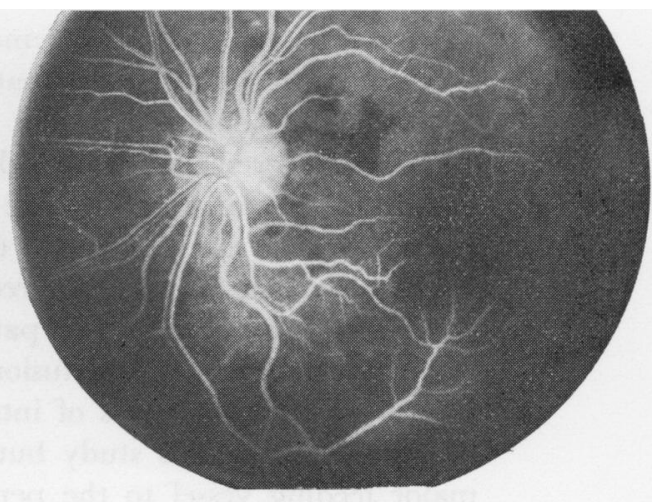

(B) $55 \mathrm{~mm} \cdot \mathrm{Hg}$

FIG. 5 Angiograms at elevated intraocular pressure reveal a choroidal filling defect adjacent to the temporal disc margin

(B)

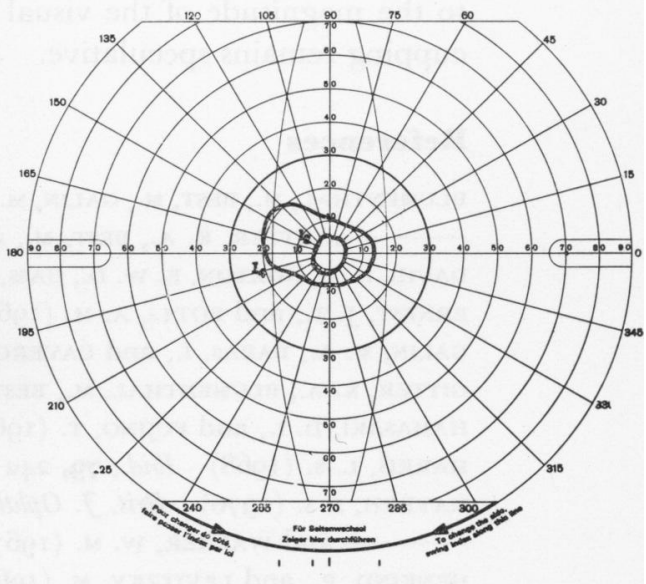


All patients in this study demonstrated the anticipated retinal arteriolar fluorescence at levels of intraocular pressure that occluded choroidal blood flow. Eight patients, however, differed from normal in that the juxtapapillary choroid contained sharply outlined defects in fluorescence temporal and adjacent to the disc at intraocular pressures in the vicinity of $60 \mathrm{~mm} . \mathrm{Hg}$. The size of these filling defects appeared to be directly related to the severity of the visual field defect. In all patients the defects filled with fluorescein when intraocular pressure was reduced below $50 \mathrm{~mm} . \mathrm{Hg}$.

This study implies that, in patients with severe glaucomatous damage to the optic nerve, there is a defect in the perfusion of blood to the peripapillary area that can be demonstrated at elevated levels of intraocular pressure. The nature of this defect cannot be determined from this study but the characteristic sharp outlines would indicate that a major feeding vessel to the peripapillary vasculature is involved by some pathological process that makes it highly vulnerable to elevated intraocular pressure. Although much data have accumulated to indicate that the peripapillary area is more vulnerable to elevated intraocular pressure than the remainder of the choroidal vasculature (Swietliczko and David, 1970; Blumenthal and others, 1970, 1971), there is no evidence that this vulnerability plays a role in the pathogenesis of optic nerve damage in glaucoma. Our results demonstrate the presence of a unique focal type of increased vulnerability of the juxtapapillary vasculature to elevated intraocular pressure in patients with glaucoma. Further studies are being conducted to determine the relationship of these focal perfusion defects to the level of intraocular pressure and to the severity of the glaucoma.

\section{Sunmary}

Fluorescein angiography was performed at acutely elevated levels of intraocular pressure in glaucoma patients with pathological cupping and visual field loss. As intraocular pressure was lowered from above the systolic ophthalmic artery pressure, the retinal blood flow resumed and was followed by the appearance of choroidal fluorescence at the posterior pole. This sequence of events is similar to the findings in normal patients, but the pattern of peripapillary choroidal fluorescence in the glaucomatous patients revealed sharply outlined defects in fluorescence at intraocular pressures above $50 \mathrm{~mm} . \mathrm{Hg}$. These juxtapapillary defects were located temporal to the disc and their size bore a direct relationship to the magnitude of the visual field loss. Their relationship to glaucomatous optic disc cupping remains speculative.

\section{References}

Blumenthal, M., Best, M., galin, m. A., and gitter, к. A. (I97I) Amer. J. Ophthal., 71, 8I9

- GitTer, K. A., Best, M., and Galin, M. A. (1970) Ibid., 69, 39

DAVID, N. J., NORTON, E. W. D., GASs, J. D., and BEAUChamp, J. (ig67) Arch. Ophthal. (Chicago), 77,6r9

ERNEST, J. T., and POTT i, A. M. (i968) Amer. 7. Ophthal., 66, $3^{80}$

galin, M. A., Baras, I., and cavero, R. (ig69) Arch. Ophthal. (Chicago), 8r, 494

gitter, K. A., Blumenthal, м., Best, m., and galin, M. A. (1970) Amer. J. Ophthal., 69, 249

hamasaki, D. I., and fujINo, T. (ig67) Arch. Ophthal. (Chicago), 78, 369

HARRIS, L. S. (I968) Ibid., 79, 242

HAYREH, s. S. (1970) Brit. J. Ophthal., 54, 289

and WAlker, w. м. (1967) Amer. 7. Ophthal., 63, 982

HENKIND, P., and LEVITZKY, M. (I969) Ibid., 68, 979

LEVITZKY, M., and HENKIND, P. (I969) Ibid., 68, 986

SWIETLICZKo, I., and DAVID, N. J. (I970) Ibid., 70, $35^{\text {I }}$ 